\title{
Evaluating Blinatumomab for the Treatment of Relapsed/Refractory ALL: Design, Development, and Place in Therapy
}

This article was published in the following Dove Press journal: Blood and Lymphatic Cancer: Targets and Therapy

\section{Audrey M Sigmund* \\ Kieran D Sahasrabudhe* \\ Bhavana Bhatnagar}

Division of Hematology, Department of Internal Medicine, The Ohio State

University and the Ohio State University

Comprehensive Cancer Center,

Columbus, OH 43210, USA

*These authors contributed equally to this work
Correspondence: Bhavana Bhatnagar

OSU Wexner Medical Center, 320

W 10th Avenue

Tel $+|-6| 4-688-7939$

Fax $+|-6| 4-293-6050$

Email Bhavana.Bhatnagar@osumc.edu

\begin{abstract}
Although adults with B-cell acute lymphoblastic leukemia (B-ALL) achieve high complete remission (CR) rates following treatment with intensive multi-agent chemotherapy regimens, up to two-thirds of these patients eventually relapse. Unfortunately, adults with relapsed or refractory $(\mathrm{R} / \mathrm{R}) \mathrm{B}-\mathrm{ALL}$ have a poor prognosis, with variable responses to salvage chemotherapy regimens and allogeneic stem cell transplant. As such, the need to develop effective and well-tolerated treatments for this patient population has been of paramount importance over the past decade. In this regard, treatment options for $\mathrm{R} / \mathrm{R}$ B-ALL patients have expanded considerably over a relatively short period of time, with the approvals of blinatumomab, inotuzumab ozogamicin and tisagenlecleucel occurring within only the past six years. Blinatumomab, a CD19 x CD3 bispecific T-cell engager (BiTE) was the first of these immune therapies to receive approval, and for many patients, is used as first-line salvage therapy. A number of large clinical trials have demonstrated improved progression-free survival and overall survival for R/R B-ALL patients receiving blinatumomab as compared to those receiving conventional salvage chemotherapy. In addition to being approved for both Philadelphia chromosome-negative and Philadelphia chromosome-positive R/R B-ALL, blinatumomab is also the only ALL therapy that carries approval for the treatment of measurable residual disease (MRD). Although blinatumomab has changed the therapeutic landscape for adults with R/R B-ALL, a number of important clinical considerations and questions remain, including the potential role of blinatumomab in the frontline setting, mechanisms of resistance, optimal goal MRD level, the role of transplant following MRD clearance, the optimal place for blinatumomab in the context of other recently approved immune-mediated therapies, and real world outcomes for patients treated outside the context of clinical trials. These issues are the focus of ongoing studies, which will hopefully inform future clinical practice regarding the utility of blinatumomab in the treatment of B-ALL patients.
\end{abstract}

Keywords: blinatumomab, BiTE antibody, B-cell acute lymphoblastic leukemia, relapsed and refractory disease, measurable residual disease, MRD

\section{Introduction}

Acute lymphoblastic leukemia (ALL) comprises the overwhelming majority of acute leukemia diagnoses in the pediatric population and approximately $20 \%$ of acute leukemia diagnoses in adults. ${ }^{1}$ Outcomes in children have dramatically improved since the 1950's, with long-term survival rates of $\sim 90 \%$. Survival outcomes in adolescents and young adults (AYAs) as well as older adults, however, are not as comparable given the presence of high-risk genetic features and presence of 
co-morbidities that limit the use of several agents that are known to be especially active in pediatric ALL. ${ }^{2}$ Furthermore, approximately one-third of standard risk and two-thirds of high-risk adult patients will eventually relapse and long-term outcomes for such patients are exceedingly poor. ${ }^{3}$ Overall complete remission $(\mathrm{CR})$ rates for relapsed or refractory $(\mathrm{R} / \mathrm{R})$ patients after first salvage therapy are typically $40 \%$ for those with Philadelphia chromosome-negative (Ph-) B-ALL with one and three year survival rates of only $26 \%$ and $11 \%$, respectively. ${ }^{2}$ Factors that are known to be associated with poor overall prognosis include the presence of measurable residual disease (MRD) following induction therapy, older age and cytogenetics (such as Ph-like ALL, complex karyotype, hypodiploidy, and others). ${ }^{4}$

In light of the poor outcomes associated with $\mathrm{R} / \mathrm{R}$ B-ALL, it became evident that novel, more effective treatment options were urgently needed for these patients. Blinatumomab (Blincyto, Amgen), a CD19 x CD3 bispecific T-cell engager (BiTE) antibody, was the first immune therapy to emerge as an effective treatment for adults with $\mathrm{R} / \mathrm{R}$ B-ALL. Its unique mechanism of action, coupled with its tolerable toxicity profile and high response rates led to approval by the US Food and Drug Administration (FDA) in 2014 for the treatment of R/R B-ALL, based on the results of the MT103-211 trial. ${ }^{5}$ Additional studies showed efficacy for blinatumomab in patients with MRD positivity including the BLAST trial in which blinatumomab was shown to improve overall survival (OS) in B-ALL patients by effectively converting MRD + patients to MRDstatus. ${ }^{6,28-30}$ This led to FDA approval in 2018 for the treatment of B-ALL patients with MRD, defined as detectable disease of $\geq 0.1 \%$. The aims of this review are to briefly describe the pharmacology of blinatumomab and to describe its current place in the therapeutic armamentarium for $\mathrm{R} / \mathrm{R}$ and MRD+ B-ALL patients. We also discuss ongoing clinical investigations that will further inform the future of blinatumomab in the treatment of B-ALL patients.

\section{Blinatumomab: Mechanism of Action and Management of Toxicities \\ Mechanism of Action}

Blinatumomab is a BiTE antibody that transiently links CD19-positive B-cells with CD3-positive T-cells, subsequently inducing both T-cell mediated lysis of B-cells as well as T-cell proliferation. It targets the pan-B-cell antigen, CD19, which is present on B-lymphocytes throughout early stages of differentiation, as early as pre-B cells. ${ }^{7}$ CD19 is expressed on more than $90 \%$ of B-cell lineage cancers and thus is an ideal target for drugs designed to treat B-cell leukemias and lymphomas. Importantly, stem cells lack CD19 expression and thus are protected from the effects of CD19 targeted therapies. ${ }^{8}$

Blinatumomab is composed of two single chain variable antibody fragments that are connected by a flexible linker (Figure 1). ${ }^{9}$ One of the single-chain variable antibody fragments binds to the epsilon chain of the T-cell receptor/CD3 complex and the other single-chain variable antibody fragment binds to CD19. By binding to CD19 expressed on the surface of cells of B-cell lineage and CD3 expressed on the surface of T-cells, blinatumomab acts as a bridge to bring B-cells and T-cells into closer proximity and results in transient engagement of tumor cells by T-cells. A signaling cascade is subsequently triggered which leads to activation of T-cells and release of cytokines which then prompts the release of cytolytic proteins, such as granzymes and perforins, into the synapse. This ultimately leads to the destruction of tumor cells by either directly inducing apoptosis or leading to the activation of caspases which then precipitate cell death. These physiologic effects caused by blinatumomab are similar to T-cell attack against other tumor cell types. ${ }^{10,11}$

\section{Preclinical and Early Clinical Trials}

Preclinical trials of blinatumomab were conducted in animal models including mice and chimpanzees. In one study to assess efficacy of blinatumomab, mice were engineered with human B-cell lymphoma xenografts and subsequently treated with blinatumomab. The authors found that blinatumomab could prevent growth of the lymphoma and essentially result in cure when administered early in tumor development. ${ }^{12}$

Safety assessment was performed in chimpanzees as blinatumomab was found only to be cross-reactive with human and chimpanzee $\mathrm{C} 19$ and CD3. In vivo analysis in chimpanzees showed that blinatumomab caused a significant but temporary increase in several serum cytokine levels including IL-2, IL-6, and IFN- $\gamma$. Cytokine levels were highest after the first infusion compared to subsequent infusions. The authors also evaluated peripheral B-cell counts and found that there was no significant decrease during the treatment period. However, in the 


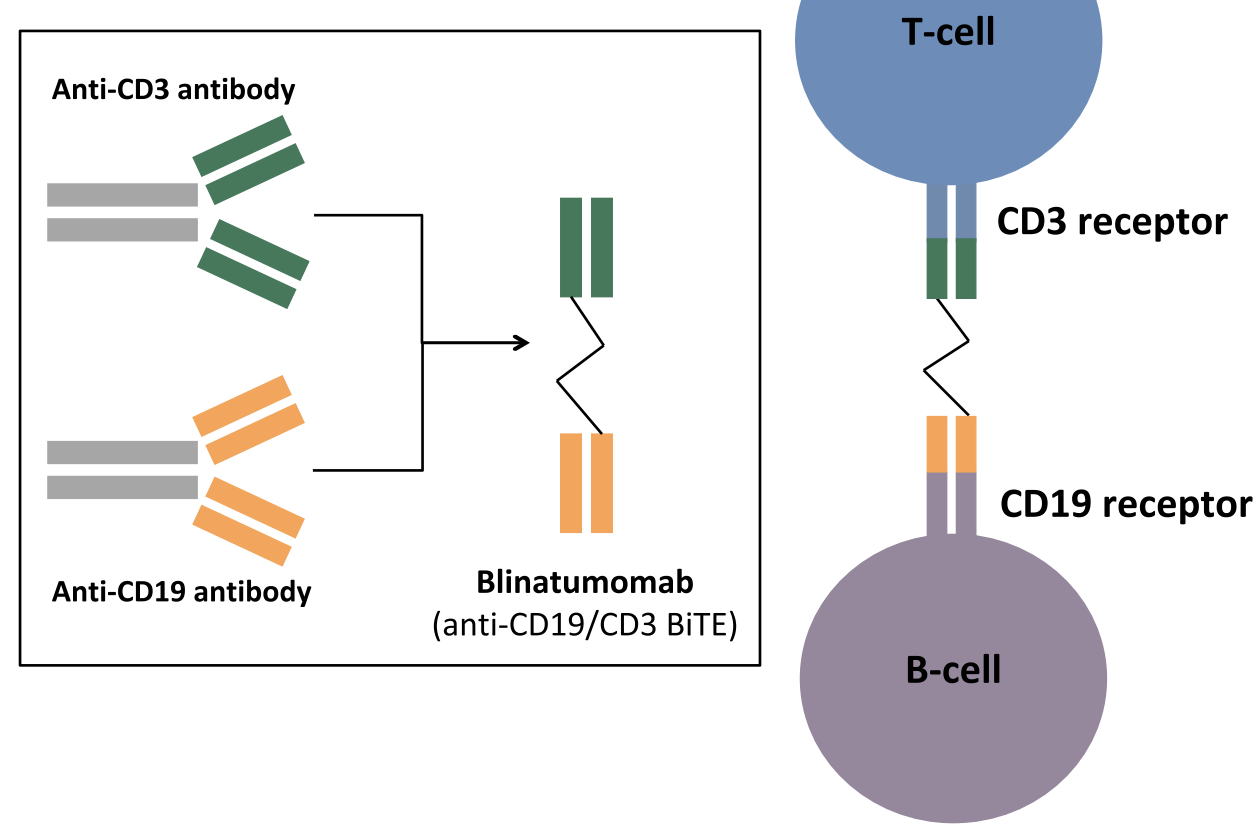

Figure I Construct and basic mechanism of action of blinatumomab. Blinatumomab is composed of two single chain variable antibody fragments that are connected by a flexible linker. It binds to CDI9 expressing B-cells and CD3 expressing T-cells and subsequently leads to immune synapses between T-cells and B-cells and results in targeting and lysing of CDI9-positive B-cells (not shown).

post-treatment period 3-5 weeks after last infusion, rates of B-cell depletion were as high as $40-70 \%{ }^{13}$

The first Phase I trials in humans were initially opened in 2001 and included patients with R/R indolent Non-Hodgkin's Lymphoma (NHL) and chronic lymphocytic leukemia (CLL). Blinatumomab was administered in short infusions and significant toxicities were noted including neurotoxicity, which led to early termination of these trials. ${ }^{14}$ A subsequent phase I trial (MT103-104) went on to evaluate blinatumomab administered in continuous intravenous infusion (cIV). This trial included 76 patients with indolent NHL and dose escalation was utilized with doses of $0.5-90 \mu \mathrm{g} /$ $\mathrm{m}^{2} / \mathrm{d}$ given over 4-8 weeks. Of the patients evaluated, $73 \%$ experienced a neurologic event with $21 \%$ experiencing a grade 3 neurologic event. The maximum tolerated dose (MTD) was $60 \mu \mathrm{g} / \mathrm{m}^{2} / \mathrm{d}$. Of those patients that were treated with the MTD, the overall response rate was $69 \% .^{15}$ The authors also found that stepwise dosing with corticosteroid prophylaxis led to few treatment discontinuations due neurotoxicity. ${ }^{15}$ These early clinical trials led to Phase II/III studies to further evaluate dosage pattern and utility in CD19+ malignancies including B-ALL.

\section{Clinical Pharmacology and Administration} Blinatumomab has similar pharmacokinetic properties to small molecules, including linear pharmacokinetics over a dose range of 5 to $90 \mu \mathrm{g} / \mathrm{m}^{2} /$ day as well as a short halflife. ${ }^{16}$ When administered as a cIV over 4 weeks, blinatumomab typically achieves steady state serum concentrations within one day. The mean volume of distribution is $4.52 \mathrm{~L}$, similar to plasma volume, and the mean clearance is $2.72 \mathrm{~L} /$ hr. ${ }^{16}$ The pharmacokinetics of blinatumomab demonstrates high variability, with fluctuations in average steady-state concentrations of up to $100 \%$ between individuals. ${ }^{16}$

Pharmacokinetics in adult patients have not been shown to be significantly impacted by body weight, body surface area, age, or sex. The impact of hepatic and renal dysfunction on blinatumomab clearance has not been evaluated with a formal study, however, hepatic impairment is not thought to significantly impact catabolism of blinatumomab given that it is a therapeutic protein; thus, dose adjustments are not recommended for those with hepatic impairment. Although renal impairment has been shown to result in an approximately $21 \%$ decrease in clearance of blinatumomab, no dosage adjustments are required for patients who have baseline mild [Creatinine clearance $(\mathrm{CrCl})$ ranging from 60 to $89 \mathrm{~mL} / \mathrm{min}$ ] or moderate $(\mathrm{CrCl}$ ranging from 30 to $59 \mathrm{~mL}$ / 
min) renal impairment. At present, there is no data available for patients with severe renal impairment $(\mathrm{CrCl}<30 \mathrm{~mL} / \mathrm{min})$ or for those on hemodialysis. ${ }^{16}$

For patients with R/R B-ALL, blinatumomab is administered as a cIV over 4 weeks with dosage schedule of 4 weeks on, 2 weeks off. Hospital admission is recommended for the initial 9 days of the first cycle and the initial 2 days of cycle 2 for close monitoring for signs of cytokine release syndrome (CRS) and neurotoxicity. To reduce the magnitude of cytokine elevation and resultant toxicities, stepwise dosing is recommended with initiation of cycle 1 , starting at $9 \mu \mathrm{g} / \mathrm{d}$ cIV for the first week followed by $28 \mu \mathrm{g} / \mathrm{d}$ cIV for the following 3 weeks with $28 \mu \mathrm{g} / \mathrm{d}$ cIV for 4 weeks in further cycles. At a cIV dose of $28 \mu \mathrm{g} / \mathrm{d}$, the average steady-stage concentration ranges from $500-700 \mathrm{pg} / \mathrm{mL} .{ }^{17}$ Pre-treatment with $20 \mathrm{mg}$ of intravenous (IV) dexamethasone should be administrated 1 hour prior to initial start of the infusion, prior to dose escalation on day 8 of cycle 1 , and prior to restarting treatment of any interruptions lasting 4 hours or longer. Prephase therapy with dexamethasone also is indicated for patients with high disease burden to prevent CRS. In the TOWER study, prephase therapy was considered mandatory for those patients with blast percentage exceeding $50 \%$ or peripheral blast count $\geq 15,000 / \mu \mathrm{L}$ and was recommended for those patients with LDH indicative of rapidly progressing disease or high extramedullary tumor load. Recommended dexamethasone dosing for pre-phase treatment is $10 \mathrm{mg} / \mathrm{m}^{2}$ / day administered orally or IV given during screening and pre-phase until initiation of cycle 1 . Dosage of dexamethasone can be increased to a maximum of $24 \mathrm{mg} /$ day in these patients. ${ }^{18}$ As blinatumomab is a cIV, patients require an infusion pump that allows for continuous intravenous home administration. Once delivered to patients, IV bags can be stored for 8 days while refrigerated and 48 hours at room temperature. $^{19}$

\section{Adverse Drug Reactions and Management}

The majority of patients receiving treatment with blinatumomab (up to 98.5\%) will experience an adverse drug reaction $(\mathrm{ADR})$ with approximately $61.8 \%$ experiencing a serious ADR, 19.1\% experiencing a fatal serious ADR, and $12.4 \%$ experiencing an ADR leading to early termination of treatment. ${ }^{18}$ ADRs occurring in $\geq 10 \%$ of blinatumomab treated patients are reported in Table 1 as compared to standard of care (SOC) chemotherapy, defined as one of four different regimens: a FLAG \pm anthracycline based regimen, HiDAC-based regimen, high-dose methotrexate based regimen, or a clofarabine based regimen. Two of the most significant ADRs are CRS and neurotoxicity which includes encephalopathy, convulsions, tremor, speech disturbances, confusion, and ataxia. ${ }^{19}$ All grades of neurologic toxicities occur in roughly $50 \%$ of patients, with grade $\geq 3$ neurotoxicity occurring in approximately $15 \%$ of patients. CRS is less common with all grades occurring in $11 \%$ and grade 3 or higher occurring in $1 \%$ of patients. Other common toxicities include pyrexia, infection, and myelosuppression. ${ }^{19}$

Initial exposure to blinatumomab can result in supraphysiologic cytokine release ultimately leading to CRS. CRS can present with a spectrum of symptoms including flu-like symptoms, hypotension, capillary leak syndrome, and multi-organ failure. It occurs exclusively within the first cycle of treatment and coincides with the highest point of T-cell expansion and cytokine release, which occurs during the first few days of blinatumomab initiation. ${ }^{20}$ Incidence and intensity of CRS is correlated with disease burden, with increased risk and severity of CRS occurring in patients with higher disease burden. Mechanisms to minimize the severity of CRS include a two-step dose escalation as well as pre-phase and pretreatment with dexamethasone as described above. ${ }^{5}$ Grade 1 or 2 CRS can typically be managed with observation or dexamethasone whereas grade 3 or 4 CRS require interruption of infusion. Grade 3 is managed by withholding the infusion until resolved then restarting at $9 \mathrm{mcg} /$ day and grade 4 typically results in permanent discontinuation. ${ }^{19}$ Tocilizumab has also been shown to play a role in management of CRS for patients with grade 3 or $4 \mathrm{CRS}^{21}$

The neurologic toxicities observed following blinatumomab therapy are thought to be related to the production of neurotoxic cytokines and chemokines after the activation of T-cells which then lead to irritation of the neuroendothelium. ${ }^{14}$ Neurotoxicity typically occurs within the first 7 days of drug initiation and is managed with dexamethasone and/or interruption of the infusion. ${ }^{5}$ For grade $\geq 3$ seizures, dose interruption is recommended along with anti-epileptic drug administration. In these cases, the infusion is typically held until symptoms are resolved to $\leq$ grade 1 for at least 3 days, then is restarted at $9 \mathrm{mcg} / \mathrm{day}$. Cases of neurotoxicity that warrant permanent discontinuation of blinatumomab include grade 3 toxicities that take more than 7 days to resolve, any grade 4 toxicity, and anytime more than one seizure occurs. ${ }^{5}$ 
Table I Adverse Drug Reactions (ADRs) Reported for $\geq 10 \%$ of Blinatumomab Treated Patients as per Package Insert with Blinatumomab Compared to Standard of Care Chemotherapy

\begin{tabular}{|c|c|c|c|c|}
\hline & \multicolumn{2}{|c|}{ Any Grade Events } & \multicolumn{2}{|c|}{ Grade $>$ or $=3$ Events } \\
\hline & $\begin{array}{l}\text { Blinatumomab } \\
(\mathrm{N}=\mathbf{2 6 7})\end{array}$ & $\begin{array}{l}\text { SOC Chemotherapy } \\
(N=109)\end{array}$ & $\begin{array}{l}\text { Blinatumomab } \\
(\mathrm{N}=\mathbf{2 6 7})\end{array}$ & $\begin{array}{l}\text { SOC Chemotherapy } \\
(\mathrm{N}=109)\end{array}$ \\
\hline \multicolumn{5}{|l|}{ Hematologic } \\
\hline Neutropenia & $84(31 \%)$ & $67(61 \%)$ & $76(28 \%)$ & $61(56 \%)$ \\
\hline Anemia & $68(25 \%)$ & 45 (4I\%) & $52(19 \%)$ & 37 (34\%) \\
\hline Thrombocytopenia & $57(21 \%)$ & 42 (39\%) & $47(18 \%)$ & $40(37 \%)$ \\
\hline Leukopenia & $21(8 \%)$ & $9(8 \%)$ & $18(7 \%)$ & $9(9 \%)$ \\
\hline \multicolumn{5}{|l|}{ Infectious } \\
\hline Pathogen unspecified & $74(28 \%)$ & $50(46 \%)$ & $40(15 \%)$ & $35(32 \%)$ \\
\hline Bacterial & $38(14 \%)$ & $35(32 \%)$ & $19(7 \%)$ & 21 (19\%) \\
\hline Viral & $30(11 \%)$ & 14 (13\%) & $4(1 \%)$ & $0(0 \%)$ \\
\hline Fungal & $27(10 \%)$ & $15(14 \%)$ & $15(14 \%)$ & $9(8 \%)$ \\
\hline \multicolumn{5}{|l|}{ Neurologic } \\
\hline Headache & $61(23 \%)$ & $30(28 \%)$ & I $(<1 \%)$ & $3(3 \%)$ \\
\hline \multicolumn{5}{|l|}{ Cardiovascular } \\
\hline Edema & $48(18 \%)$ & $20(18 \%)$ & $3(1 \%)$ & I (l\%) \\
\hline Arrhythmia & $37(14 \%)$ & $18(17 \%)$ & $5(2 \%)$ & $0(0 \%)$ \\
\hline \multicolumn{5}{|l|}{ Other } \\
\hline Pyrexia & 147 (55\%) & $43(39 \%)$ & $15(6 \%)$ & $4(4 \%)$ \\
\hline Infusion-related & 79 (30\%) & $9(8 \%)$ & $9(3 \%)$ & I (I\%) \\
\hline Transaminitis & 40 (15\%) & $13(12 \%)$ & $22(8 \%)$ & $7(6 \%)$ \\
\hline CRS & $37(14 \%)$ & $0(0 \%)$ & $8(3 \%)$ & $0(0 \%)$ \\
\hline Rash & 31 (12\%) & 21 (19\%) & $2(1 \%)$ & $0(0 \%)$ \\
\hline
\end{tabular}

There are several other ADRs that have been documented with blinatumomab. Pyrexia is the most common ADR, occurring in approximately $55 \%$ of patients with $6 \%$ falling within grade 3 or higher. Myelosuppression is also common, with neutropenia occurring in $31 \%$ of patients, anemia in $25 \%$, and thrombocytopenia in $21 \%$. Infectious complications occur in $>60 \%$ of patients. Edema was seen in $18 \%$ of patients with arrhythmia occurring in $14 \%$. Transaminitis also can occur in approximately $15 \%$ of patients. Twelve percent of patients experience rash. ${ }^{19}$ Tumor lysis syndrome (TLS) is very rare in blinatumomab-treated patients. The severity and frequency of ADRs generally decrease after the first cycle, likely related to a lesser degree of cytokine release following later cycles of treatment.

\section{Blinatumomab Treatment Indications}

\section{Blinatumomab for R/R ALL}

Blinatumomab now plays a key role in the treatment of patients with $\mathrm{R} / \mathrm{R}$ B-ALL after a series of clinical trials demonstrated improvement in outcomes compared to traditional salvage chemotherapy. A summary of prior trials for treatment of B-ALL with blinatumomab is shown in Table 2. The initial trial that led to FDA approval in 2014 was a large multicenter, single-arm Phase II study (MT103-211, NCT01466179) $^{5}$ in which 189 patients with Ph- R/R B-ALL were enrolled to evaluate the clinical efficacy of blinatumomab. To minimize CRS and neurotoxicity, a step-wise dose escalation was utilized, starting at $9 \mu \mathrm{g} /$ day for the first week followed by $28 \mu \mathrm{g} /$ day for the subsequent 3 weeks. Treatment was given in 6 week cycles with 4 weeks of treatment and 2 weeks off. After two cycles of treatment, $43 \%$ of patients achieved a CR/ CR with partial hematologic recovery (CRh), with 33\% obtaining a CR and $10 \%$ a CRh. Median relapse free survival (RFS) was 5.9 months with a median follow-up of 8.9 months and the median OS was 6.1 months with a median follow-up of 9.8 months. Of the patients that achieved a $\mathrm{CR} / \mathrm{CRh}, 40 \%$ underwent allogeneic hematopoietic stem cell transplant (allo-HSCT). Twenty-percent 
Table 2 Summary of Prior Trials for Treatment of B-ALL with Blinatumomab

\begin{tabular}{|c|c|c|}
\hline R/R B-ALL & & \\
\hline $\begin{array}{l}\text { Authors. Publication } \\
\text { Details Reference } \\
\text { Number }\end{array}$ & Title & Results Summary \\
\hline $\begin{array}{l}\text { Topp, M.S. et al Lancet } \\
\text { Oncol, } 2015.16(1) \text { : } \\
\text { p. } 57-66 .^{5}\end{array}$ & $\begin{array}{l}\text { Safety and activity of blinatumomab for adult patients with } \\
\text { relapsed or refractory B-precursor acute lymphoblastic } \\
\text { leukaemia: a multicentre, single-arm, phase } 2 \text { study }\end{array}$ & $\begin{array}{l}43 \% \text { CR/CRh rate. Median RFS } 5.9 \text { months. Median OS } \\
6.1 \text { months }\end{array}$ \\
\hline $\begin{array}{l}\text { Kantarjian, H. et al } \\
\text { N Engl J Med, } 2017 . \\
376(9): \text { p. } 836-847 .^{18}\end{array}$ & $\begin{array}{l}\text { Blinatumomab versus Chemotherapy for Advanced Acute } \\
\text { Lymphoblastic Leukemia }\end{array}$ & $\begin{array}{l}\text { CR rate } 34 \% \text { for blinatumomab vs } 16 \% \text { for chemotherapy } \\
(p<0.001) \text {. OS } 7.7 \text { months for blinatumomab vs } 4 \text { months } \\
\text { for chemotherapy }(p=0.01)\end{array}$ \\
\hline $\begin{array}{l}\text { Martinelli G. et al J Clin } \\
\text { Oncol, } 2017.35(16) \text { : } \\
\text { p. } 1795-1802 .^{22}\end{array}$ & $\begin{array}{l}\text { Complete Hematologic and Molecular Response in Adult } \\
\text { Patients With Relapsed/Refractory Philadelphia } \\
\text { Chromosome-Positive B-Precursor Acute Lymphoblastic } \\
\text { Leukemia Following Treatment With Blinatumomab: } \\
\text { Results From a Phase II, Single-Arm, Multicenter Study }\end{array}$ & $\begin{array}{l}36 \% \text { CR/CRh rate. Median RFS } 6.7 \text { months. Median OS } \\
7.1 \text { months }\end{array}$ \\
\hline \multicolumn{3}{|l|}{ MRD+ B-ALL } \\
\hline $\begin{array}{l}\text { Topp, M.S. et al J Clin } \\
\text { Oncol, } 201 \text { I. } 29 \text { (I8): } \\
\text { p. } 2493-8 .^{28}\end{array}$ & $\begin{array}{l}\text { Targeted therapy with the T-cell-engaging antibody } \\
\text { blinatumomab of chemotherapy-refractory minimal } \\
\text { residual disease in B-lineage acute lymphoblastic leukemia } \\
\text { patients results in high response rate and prolonged } \\
\text { leukemia-free survival }\end{array}$ & $\begin{array}{l}80 \% \text { achieved MRD negativity. }{ }^{28} \text { RFS } 65 \% \text { at median } \\
\text { follow-up of } 33 \text { months. }{ }^{29} 50 \% \text { RFS at median follow up of } \\
50.8 \text { months. }{ }^{6}\end{array}$ \\
\hline $\begin{array}{l}\text { Gokbuget, N. et al } \\
20|8.13|(\mid 4): \\
\text { p. }|522-153| .^{30}\end{array}$ & $\begin{array}{l}\text { Blinatumomab for minimal residual disease in adults with } \\
\text { B-cell precursor acute lymphoblastic leukemia }\end{array}$ & $\begin{array}{l}\text { 78\% achieved MRD negativity. Median RFS } 18.9 \text { months. } \\
\text { Median OS } 36.5 \text { months }\end{array}$ \\
\hline
\end{tabular}

of patients who received blinatumomab in this study were alive after two years, which was superior to historical data with traditional chemotherapy. Based on this study, the estimated long-term survival (at least 60 months) was $12.4 \%$ as compared to $5.4 \%$ with salvage chemotherapy. These findings suggested that blinatumomab may have superior outcomes in patients with $\mathrm{R} / \mathrm{R} \mathrm{B}-\mathrm{ALL}$ when compared to salvage chemotherapy and thus led to future randomized trials to further evaluate blinatumomab in comparison to salvage chemotherapy.

The landmark randomized Phase III TOWER study directly evaluated the efficacy of blinatumomab compared to four commonly employed salvage chemotherapy regimens. ${ }^{18}$ The study enrolled $405 \mathrm{Ph}-\mathrm{B}-\mathrm{ALL}$ patients who were randomized in a $2: 1$ ratio with 271 patients receiving blinatumomab and 124 patients receiving salvage chemotherapy. Patients received up to 2 cycles of induction and those patients who achieved a morphologic remission then received up to 3 cycles of consolidation, with those with continued morphologic remission subsequently receiving up to 12 months of maintenance. The dosage schedule for both induction and maintenance blinatumomab was similar to in MT103-211 with maintenance treatment given as a 4 week cIV dosed every 12 weeks. Patients randomized to receive salvage chemotherapy were eligible to receive one of four physicians choice regimens. Forty-nine patients (45\%) received high-dose cytosine arabinoside and granulocyte colony stimulating factor with or without anthracycline, 19 patients (17\%) received high-dose cytosine arabinosidebased regimens, 22 patients $(20 \%)$ received methotrexatebased regimens, and 19 patients (17\%) received clofarabinebased regimens. In comparison to patients receiving salvage chemotherapy, blinatumomab-treated patients had improved CR rates $(34 \%$ vs $16 \%, P<0.001)$ and OS (7.7 months versus 4 months, $P=0.01$ ) in R/R B-ALL patients. This study confirmed that treatment with blinatumomab results in significantly longer OS in adult patients with $\mathrm{R} / \mathrm{R}$ B-ALL as compared to conventional chemotherapy. ${ }^{18}$

Additional trials have also focused on evaluating the role of blinatumomab in treatment of patients with $\mathrm{Ph}+\mathrm{R} /$ R B-ALL. A Phase II, single arm, multicenter study of Ph + B-ALL patients by Martinelli et al evaluated the efficacy 
of blinatumomab for treatment of $\mathrm{Ph}+\mathrm{B}-\mathrm{ALL}$ patients who progressed after failure of TKI based therapy. ${ }^{22}$ The study included 45 patients with $\mathrm{Ph}+\mathrm{B}-\mathrm{ALL}$ who had relapsed while on a TKI or had been refractory to at least one second generation TKI. Of the 45 patients, $36 \%$ achieved a $\mathrm{CR} / \mathrm{CRh}$ after the first two cycles and $88 \%$ of the $\mathrm{CR} / \mathrm{CRh}$ responders achieved a complete MRD response with $44 \%$ of responders proceeding with alloHSCT. Median OS was 7.1 months and median RFS was 6.7 months. Blinatumomab has also been evaluated in combination with TKIs for treatment of $\mathrm{R} / \mathrm{R} \mathrm{Ph}+\mathrm{ALL}$. A retrospective study by King et al evaluated the utility of blinatumomab in combination with an oral TKI as consolidation therapy for patients with $\mathrm{Ph}+\mathrm{B}$-ALL. This study demonstrated that Blinatumomab + TKI resulted in eradication of MRD in the majority of patients with $\mathrm{Ph}+$ ALL and this therapy overall was well tolerated. ${ }^{23}$ Another retrospective study by Assi et al assessed Blinatumomab + TKI for treatment of $\mathrm{Ph}+$ positive patients. The study included 12 patients, 9 with $\mathrm{Ph}+\mathrm{ALL}$ and 3 with chronic myeloid leukemia (CML) in blast crisis. Of these patients, $75 \%(9 / 12)$ achieved complete molecular response and the treatment was safe. ${ }^{24}$ Additional prospective studies are needed to further characterize the role of Blinatumomab in $\mathrm{Ph}+\mathrm{B}-\mathrm{ALL}$ compared to conventional chemotherapy as well as in combination with TKIs.

\section{Blinatumomab in MRD+ Disease}

Eradication of MRD is another active area of research in ALL. MRD describes low-level disease that is unable to be detected by conventional cytomorphology and is only detectable by more sensitive techniques including flow cytometry, polymerase chain reaction assays, and nextgeneration sequencing. It has become increasingly clear that MRD positivity is one of the most significant independent prognostic factors in B-ALL patients and that achievement of MRD negativity is crucial for improving patient outcomes. ${ }^{25-27}$

Several clinical trials have evaluated the efficacy of blinatumomab in MRD-positive B-ALL patients. Topp and colleagues conducted a phase II study in which blinatumomab was administered to 21 patients in first CR after induction, and at least one round of consolidation chemotherapy, who had detectable MRD defined as $\geq 1$ $\mathrm{x} 10^{-4}$. The dose of blinatumomab administered to MRDpositive patients was lower ( $15 \mu \mathrm{g} /$ day, 4 weeks on and 2 weeks off) compared to the dosing used for salvage therapy. Of the 20 evaluable patients, $16(80 \%)$ achieved
MRD negativity, all of which occurred after one cycle of blinatumomab. ${ }^{28}$ Patients with a matched donor were permitted to undergo allo-HSCT at any time after the first cycle of blinatumomab therapy, but the study was not powered to assess the impact of HSCT after blinatumomab. Forty-five percent of the evaluable patients went on to receive a transplant. An interim efficacy analysis conducted after a median follow up of 33 months found an overall RFS rate of $61 \%$. The RFS rate was $65 \%$ among the 9 patients who had undergone transplant and $60 \%$ among the 11 patients who had not undergone transplant. ${ }^{29}$ Patients completed follow-up visits for up to 5 years, and the final analysis was conducted after a median follow up of 50.8 months. Fifty percent of the 20 total evaluable patients remained in remission at the final analysis. Stratifying the results according to transplant status showed that $56 \%(5 / 9)$ of patients who had received a transplant were in remission and $45 \%(5 / 11)$ of patients who had not received a transplant remained in remission. ${ }^{6}$

This study was followed by the landmark phase II BLAST trial led by Gökbuget and colleagues, in which blinatumomab was administered for up to 4 cycles in patients with B-ALL in first or later hematologic CR and with persistent or recurrent $\mathrm{MRD} \geq 10^{-3}$ after at least 3 cycles of intensive chemotherapy. The dosing schedule for each cycle of blinatumomab in this trial was also $15 \mu \mathrm{g}$ / day, 4 weeks on and 2 weeks off. A total of 116 patients were enrolled, and eligible patients were permitted to undergo allo-HSCT at any time after cycle 1 of blinatumomab therapy. Of the 113 evaluable patients for the primary endpoint of MRD response, 78\% achieved MRD negativity after one cycle of blinatumomab. Two additional patients achieved MRD negativity after cycle 2 with no additional patients achieving MRD negativity after cycle 3 or 4 . Secondary end point analyses involving survival and transplantation were conducted in 110 patients with $\mathrm{Ph}$ - disease. Median RFS and OS were 18.9 months and 36.5 months, respectively, with a median follow up of 30 months. Notably, patients achieving MRD negativity after cycle 1 of blinatumomab had significantly better survival outcomes compared to MRD nonresponders with a median RFS of 23.6 vs 5.7 months $(P=0.002)$ and median OS of 38.9 vs 12.5 months $(P=0.002)$ for MRD responders and MRD nonresponders, respectively. These data thereby demonstrated a direct patient benefit for the conversion of MRD positivity to MRD negativity. Importantly, patients in second 
or third CR had significantly inferior RFS and OS compared to patients in first $\mathrm{CR}$ despite having similar rates of MRD response to blinatumomab, suggesting that administering blinatumomab for MRD eradication in first CR is more beneficial compared to using it in subsequent remissions. Sixty-seven percent (74/110) included in the secondary endpoint analysis underwent allo-HSCT. At a median follow up of 24 months, 25\% (9/36) of patients who had not received HSCT or chemotherapy after blinatumomab remained in CR whereas $49 \%$ (36/74) of patients who had undergone HSCT remained in CR. This study, too, was not powered to assess the impact of allo-HSCT after blinatumomab. ${ }^{30}$ However, in light of the obvious survival benefit conferred through conversion to MRDnegativity, blinatumomab received FDA approval in 2018 for patients with B-ALL in CR with MRD $10^{-3}(0.1 \%)$ or greater.

In an effort to determine whether blinatumomab provides the same survival benefit for $\mathrm{Ph}+\mathrm{B}$-ALL patients, Richard-Carpentier et al sought to address this question in their ongoing phase II study in which blinatumomab was administered to $\mathrm{Ph}$ - and $\mathrm{Ph}+\mathrm{B}-\mathrm{ALL}$ patients with persistent or recurrent MRD of $\geq 10^{-4}$. In this trial, patients were able to receive up to 5 cycles of blinatumomab therapy followed by allo-HSCT any time after cycle 1 . Of note, $\mathrm{Ph}$ + B-ALL patients were treated with physician's choice TKI in addition to blinatumomab. Of the 25 patients who were enrolled between December 2015 and June 2019, MRD negativity was achieved in $75 \%$ of patients with $\mathrm{Ph}+$ disease and $80 \%$ of patients with $\mathrm{Ph}$ - disease $(P=1.00)$, and there was no significant difference in 2-year RFS or OS according to Ph status. Results of longer follow up will be informative, particularly in regards to the outcomes for patients with $\mathrm{Ph}+$ disease who are treated with blinatumomab plus TKI therapy. ${ }^{31}$

\section{Future Study Directions}

Although blinatumomab has earned its place as an effective and well tolerated treatment option for R/R B-ALL patients and those with MRD+ disease, several key questions remain that are currently being evaluated in ongoing clinical trials, as described below and summarized in Table 3 .

\section{What is the Optimal MRD Level in Which to Use Blinatumomab?}

Blinatumomab is currently FDA approved for patients with MRD of $10^{-3}$ or greater based on the trial conducted by Gökbuget and colleagues. ${ }^{30}$ However, other clinical trials studying blinatumomab in the MRD + setting have used different MRD thresholds for blinatumomab administration. ${ }^{28,31}$ This speaks to the controversial nature of MRD thresholds and the lack of standardization regarding the level of MRD that should be used to inform clinical decisions. Improvement in MRD detection techniques has also allowed for increased sensitivity. For example, the FDA-approved ClonoSeq technology uses nextgeneration sequencing of immunoglobulin receptor genes as well as regions of the genome that are frequently translocated. This assay is able to detect residual disease at a level of $10^{-6.32}$ Continued technologic improvements will likely continue to allow us to detect increasingly small amounts of MRD. It will therefore be important to continue to assess whether patients with increasingly low levels of detectable MRD benefit from treatment with blinatumomab and to continue to refine our understanding of the most appropriate MRD threshold for treatment.

\section{Do All Patients Who Achieve MRD-Negativity Following Blinatumomab Benefit from Transplant?}

At present, allo-HSCT is recommended for ALL patients who have detectable MRD following standard frontline induction therapy. ${ }^{33,34}$ However, it remains unknown whether MRD+ patients who clear their MRD after being treated with blinatumomab derive benefit from transplant. For instance, Topp and colleagues reported that $45 \%$ of patients who had not undergone transplant remained in remission at median follow up of 50.8 months compared to $56 \%$ of the patients who had received a transplant. ${ }^{28}$ This was further supported in the BLAST study in which $25 \%$ of the patients who had not undergone transplant remained in $\mathrm{CR}$ at a median follow up of 24 months compared to $49 \%$ who had undergone transplant. Taken together, these data suggest that not all MRD responders necessarily require a transplant. However, these trials were not powered to assess the impact of transplant after blinatumomab, which will be an important consideration to address in future studies. For MRD responders who are ineligible for allo-HSCT, future studies designed to determine the optimal number of cycles of blinatumomab in addition whether or not combination therapies are needed will also be important to address. For transplant recipients, the role of blinatumomab in the post-transplant 
Table 3 Summary of Ongoing Trials for Treatment of B-ALL with Blinatumomab

\begin{tabular}{|c|c|c|}
\hline Title & Trial Details & Preliminary Results \\
\hline $\begin{array}{l}\text { Phase II Study of Blinatumomab in Patients } \\
\text { with B-Cell Acute Lymphoblastic Leukemia } \\
\text { (B-ALL) with Positive Measurable Residual } \\
\text { Disease (MRD) }\end{array}$ & $\begin{array}{l}\text { Eligible adult patients have MRD } 10^{-4} \text { or } \\
\text { greater. Ph- patients receive single agent } \\
\text { blinatumomab. } \mathrm{Ph}+\text { patients receive } \\
\text { blinatumomab plus TKI }\end{array}$ & $\begin{array}{l}\text { MRD negativity achieved in } 75 \% \text { of } \mathrm{Ph}+ \\
\text { patients and } 80 \% \text { of Ph- patients for first } 25 \\
\text { patients enrolled. No significant difference in } \\
2 \text { year RFS or OS by Ph status. }{ }^{31}\end{array}$ \\
\hline $\begin{array}{l}\text { Combination Chemotherapy With or Without } \\
\text { Blinatumomab in Treating Patients With Newly } \\
\text { Diagnosed BCR-ABL-Negative B Lineage } \\
\text { Acute Lymphoblastic Leukemia } \\
\text { (NCT02003222) }\end{array}$ & $\begin{array}{l}\text { Phase III trial. Adults with newly diagnosed Ph- } \\
\text { disease are randomized to receive induction, } \\
\text { intensification, consolidation, and maintenance } \\
\text { therapy either with or without blinatumomab }\end{array}$ & \\
\hline $\begin{array}{l}\text { Blinatumomab and Combination } \\
\text { Chemotherapy or Dasatinib, Prednisone, and } \\
\text { Blinatumomab in Treating Older Patients With } \\
\text { Acute Lymphoblastic Leukemia } \\
\text { (NCT021434/4) }\end{array}$ & $\begin{array}{l}\text { Phase II trial in adults } 65 \text { and older. Newly } \\
\text { diagnosed } \mathrm{Ph} \text { - patients receive blinatumomab + } \\
\mathrm{POMP} \text {. Newly diagnosed } \mathrm{Ph}+, \mathrm{R} / \mathrm{R} \mathrm{Ph}+\text { and } \mathrm{Ph}- \\
\text { like patients receive blinatumomab, dasatinib, } \\
\text { and prednisone }\end{array}$ & $\begin{array}{l}66 \% \mathrm{CR} / \mathrm{Cri} \text { rate for newly diagnosed } \mathrm{Ph}- \\
\text { patients treated with blinatumomab + POMP. }\end{array}$ \\
\hline $\begin{array}{l}\text { Dasatinib-Blinatumomab Combination for the } \\
\text { Front-Line Treatment of Adult Ph+ ALL } \\
\text { Patients. Updated Results of the Gimema } \\
\text { LAL2II6 D-Alba Trial. }\end{array}$ & $\begin{array}{l}\text { Ongoing phase II multicenter study combining } \\
\text { blinatumomab with dasatinib for frontline } \\
\text { therapy in patients with } \mathrm{Ph}+\mathrm{B}-\mathrm{ALL} \text {. }\end{array}$ & $\begin{array}{l}\text { Molecular response in } 80 \% \text { of patients after } 4 \\
\text { cycles of blinatumomab with a } 12 \text { month OS } \\
\text { and disease free survival of } 94.2 \% \text { and } 87.8 \% .{ }^{41}\end{array}$ \\
\hline $\begin{array}{l}\text { Inotuzumab Ozogamicin and Blinatumomab in } \\
\text { Treating Patients With Newly Diagnosed, } \\
\text { Recurrent, or Refractory CD22-Positive } \\
\text { B-Lineage Acute Lymphoblastic Leukemia } \\
\text { (NCT037398I4) }\end{array}$ & $\begin{array}{l}\text { Phase II trial. Adults with newly diagnosed or } \\
\mathrm{R} / \mathrm{R} \mathrm{CD} 22+, \mathrm{Ph} \text { - disease are treated with } \\
\text { inotuzumab followed by blinatumomab }\end{array}$ & \\
\hline $\begin{array}{l}\text { Updated Results from the Phase II Study of } \\
\text { Hyper-CVAD in Sequential Combination with } \\
\text { Blinatumomab in Newly Diagnosed Adults } \\
\text { with B-Cell Acute Lymphoblastic Leukemia } \\
\text { (B-ALL). }\end{array}$ & $\begin{array}{l}\text { Adults with newly diagnosed disease receive } \\
\text { sequential hyper-CVAD and blinatumomab } \\
\text { followed by maintenance POMP plus } \\
\text { blinatumomab. }\end{array}$ & $\begin{array}{l}\text { I00\% CR rate with } 96 \% \text { achieving MRD } \\
\text { negativity of } 10^{-4} \text { or less in first } 27 \text { patients. } 12 \\
\text { month estimated RFS } 76 \% \text { and OS } 89 \%{ }^{42}\end{array}$ \\
\hline $\begin{array}{l}\text { Preliminary Minimal Residual Disease Analysis } \\
\text { of the Australasian Leukaemia \& Lymphoma } \\
\text { Group (ALLG) ALL8 Study of Front-Line } \\
\text { Blinatumomab with Chemotherapy in Adults } \\
\text { with Ph Negative B-Cell Acute Lymphoblastic } \\
\text { Leukaemia }\end{array}$ & $\begin{array}{l}\text { Phase II trial. Adults with newly diagnosed } \\
\text { disease receive blinatumomab alternating with } \\
\text { part B hyper-CVAD }\end{array}$ & $\begin{array}{l}\text { Seven of the first ten patients achieved MRD of } \\
10^{-4} \text { or greater by completion of one } \\
\text { consolidation cycle. }{ }^{43}\end{array}$ \\
\hline $\begin{array}{l}\text { Blinatumomab and Nivolumab With or } \\
\text { Without Ipilimumab in Treating Patients With } \\
\text { Poor-Risk Relapsed or Refractory CDI9+ } \\
\text { Precursor B-Lymphoblastic Leukemia } \\
\text { (NCT02879695) }\end{array}$ & $\begin{array}{l}\text { Phase I trial. Adults with poor-risk, relapsed, } \\
\text { or refractory disease are treated with } \\
\text { blinatumomab plus either single agent } \\
\text { nivolumab or combination nivolumab/ } \\
\text { ipilimumab }\end{array}$ & \\
\hline $\begin{array}{l}\text { Blinatumomab and Pembrolizumab for Adults } \\
\text { With Relapsed/Refractory B-cell Acute } \\
\text { Lymphoblastic Leukemia With High Marrow } \\
\text { Lymphoblasts (NCT03160079) }\end{array}$ & $\begin{array}{l}\text { Phase } \mathrm{I} / \mathrm{II} \text { Trial. Adults with } \mathrm{R} / \mathrm{R} \text { disease and } \\
\geq 50 \% \text { blasts in bone marrow are treated with } \\
\text { blinatumomab plus pembrolizumab }\end{array}$ & \\
\hline
\end{tabular}


Table 3 (Continued).

\begin{tabular}{|l|l|l|}
\hline Title & Trial Details & Preliminary Results \\
\hline $\begin{array}{l}\text { Pembrolizumab and Blinatumomab in Treating } \\
\text { Participants with Recurrent or Refractory } \\
\begin{array}{l}\text { Acute Lymphoblastic Leukemia } \\
\text { (NCT035/2405) }\end{array}\end{array}$ & $\begin{array}{l}\text { Phase I/II Trial. Adults with R/R disease receive } \\
\text { blinatumomab plus pembrolizumab }\end{array}$ \\
\hline $\begin{array}{l}\text { Pembro + Blina Combination in Pediatric and } \\
\text { Young Adult Patients with Relapsed/Refractory }\end{array}$ & $\begin{array}{l}\text { Pilot study of blinatumomab plus } \\
\text { pembrolizumab in patients age I-40 with R/R } \\
\text { Acute Leukemia or Lymphoma }\end{array}$ & \\
(NCT03605589) & & \\
\hline
\end{tabular}

maintenance setting is also an important issue, which is currently under investigation. ${ }^{35}$

\section{What is the Optimal Place of Blinatumomab in the Context of Other Immunological Therapeutic Strategies?}

Two other promising immunological therapies that are now FDA approved for R/R B-ALL patients are inotuzumab ozogamicin and CAR-T cell therapy. Inotuzumab ozogamicin is an anti-CD22 antibody that is attached to the cytotoxic agent calicheamicin. An early phase II trial by Kantarjian et al showed a $\mathrm{CR} / \mathrm{CRi}$ rate of $57 \%$ with $63 \%$ of these responders achieving a complete molecular response $(\mathrm{CMR}){ }^{36}$ An additional phase $\mathrm{I} / \mathrm{II}$ trial by DeAngelo et al had similar response rates with $68 \%$ of patients achieving a $\mathrm{CR} / \mathrm{CRi}$ and $84 \%$ of these responders achieving MRD negativity. ${ }^{37}$ A subsequent phase III trial, the INO-VATE study, comparing inotuzumab to SOC chemotherapy showed a significantly higher CR/CRi rate with inotuzumab $(80.7 \%$ vs $29.4 \%)$. Patients randomized to SOC chemotherapy received either FLAG (fludarabine, cytarabine, and granulocyte colony-stimulating factor), cytarabine plus mitoxantrone, or HiDAC. Overall survival was also superior in the inotuzumab group (7.7 vs 6.7 months $P=0.04)$. This survival difference has remained durable over time with the 2-year OS rate of $22.8 \%$ versus $10 \%$ with SOC; $P=0.01 .^{38}$ Common toxicities of inotuzumab included myelosuppression as well as increased risk for veno-occlusive disease (VOD) post-allo-SCT. The rate of VOD was as high as $23 \%$ in the initial phase II trial but was lower at $11 \%$ in the INO-VATE study, in which dualalkylating therapy was the only significant covariate for development of VOD. ${ }^{36-38}$

Chimeric antigen receptor T cell therapy (CAR-T) has also recently emerged as an option for treatment of patients with $R /$
R B-ALL. CAR-T cells are auto-reactive T-cells that have been engineered to recognize and target cells expressing a specific marker. The primary CAR-T cells that are studied for B-ALL patients are CD19 targeted CAR-T cells. A landmark phase II trial of CAR-T cell therapy for R/R B-ALL patients was conducted in 75 patients aged 3-21 years old. These patients received tisagenlecleucel (Kymriah), an anti-CD19 CAR-T cell therapy. Of those patients who received tisagenlecleucel infusion, $81 \%$ of patients achieved MRD-negativity within 3 months. At 12 months, the rate of event free survival and OS were $50 \%$ and $76 \%$, respectively. Median duration of remission was not reached. Most common toxicities were CRS, which occurred in $77 \%$ of patients with $48 \%$ of patients requiring tocilizumab, as well as neurologic events, which occurred in $40 \%$ of patients. ${ }^{39}$

The optimal sequence for these therapies is not always clear, but there are several important considerations when deciding which of these treatments to use and when. CAR-T cell therapy is currently only approved for patients aged 21 years old and younger although there are ongoing trials to assess its role in adult patients (NCT01044069, NCT01865617, NCT02614066). When deciding between blinatumomab and inotuzumab in patients with leukemia that is both CD19 and CD22 positive, blinatumomab is preferred for patients that will be proceeding to allo-HCT due to increased risk of VOD with inotuzumab. However, if a patient has high tumor burden including extramedullary disease, inotuzumab is often preferred because response rates with inotuzumab do not correlate with disease burden, whereas blinatumomab has lower response rates in the setting of high tumor burden. ${ }^{5,37}$ Inotuzumab is also favorable to blinatumomab for patients with CNS disease due to risk of neurotoxicity with blinatumomab. ${ }^{19}$ Blinatumomab is preferable for patients with MRD-positive disease, as inotuzumab currently is not approved for these patients. ${ }^{30}$ 


\section{Does Blinatumomab Have a Place in the Frontline Setting for B-ALL Patients?}

Given the encouraging results seen with blinatumomab in the $\mathrm{R} / \mathrm{R}$ and $\mathrm{MRD}+$ setting, it is under active investigation in a number of frontline clinical trials. ECOG E1910 (NCT02003222) is a randomized phase III study comparing chemotherapy plus blinatumomab to chemotherapy alone in adults with newly diagnosed Ph- B-ALL. This trial has completed enrollment and results are expected to be available in the near future. SWOG S1318 (NCT02143414), is an open-label phase II clinical trial for older adults ( $\geq 65$ years) with untreated $\mathrm{Ph}$ - or $\mathrm{Ph}+\mathrm{B}-\mathrm{ALL}$ in which blinatumomab plus POMP (prednisone, vincristine, methotrexate, and 6-mercaptopurine) is used as induction therapy. $\mathrm{Ph}+$ patients also receive dasatinib as part of their treatment as well. Interim analysis of untreated $\mathrm{Ph}$ - patients showed that blinatumomab plus POMP as frontline therapy was associated with a CR/CRi rate of $66 \%$ and that $92 \%$ of these responders with available MRD data had achieved MRD negativity after one cycle of blinatumomab. ${ }^{40}$ The D-Alba trial is an ongoing phase II multicenter study combining blinatumomab with dasatinib for frontline therapy in patients with $\mathrm{Ph}+\mathrm{B}-\mathrm{ALL}$. Patients were treated with dasatinib monotherapy for induction for 85 days with blinatumomab added for consolidation for those patients who achieved a complete hematologic response with dasatinib induction. Interim analysis showed a molecular response in $80 \%$ of patients after 4 cycles of blinatumomab with a 12-month OS and disease-free survival of $94.2 \%$ and $87.8 \%$, respectively. ${ }^{41}$

Another unique ongoing frontline phase II study is Alliance A041703 (NCT03739814) in which older adults with untreated CD22-positive B-ALL are treated with inotuzumab induction, followed by blinatumomab consolidation therapy. Richard-Carpentier and colleagues are currently conducting a phase II study evaluating treatment of adults with newly diagnosed B-ALL with sequential hyper-CVAD and blinatumomab followed by maintenance with POMP and blinatumomab. Interim analysis of 27 patients has shown a $100 \%$ CR rate with $96 \%$ of patients achieving MRD of $10^{-4}$ or less and a 12 month estimated RFS of $76 \%$ and OS of 89\%. ${ }^{42}$ Lastly, ALLG ALL8 (ACTRN12617000084381) is a phase II study of blinatumomab alternating with "part B" cycles of hyper-CVAD for adults with newly diagnosed B-ALL. Of the first 10 patients treated on this study, 7 achieved MRD of $10^{-4}$ or greater by completion of one consolidation. $^{43}$

\section{What are the Mechanisms of Resistance to Blinatumomab?}

Another important question to consider is mechanisms of resistance to blinatumomab. One potential mechanism of resistance to CD19-directed therapy is target antigen loss, which is seen in a significant subset of patients undergoing CD19-directed CAR-T cell therapy. ${ }^{44}$ This phenomenon is known to occur in patients treated with blinatumomab, but appears to be a less common mechanism of resistance compared to CAR-T cell therapy. ${ }^{45}$ Treatment of KMT2A (formerly $M L L$ )-rearranged B-ALL with blinatumomab has also been reported to be associated with subsequent lineage switch to AML, which is another potential mechanism of resistance. ${ }^{46-49}$ Additionally, as the efficacy of blinatumomab is dependent on the activity of T-cells, down-regulation of T-cell activity has also been studied as a potential mechanism of resistance to blinatumomab. Studies have shown that markers of T-cell exhaustion including PD-L1 and PD1 are increased in the setting of blinatumomab therapy thereby decreasing T-cell activity. ${ }^{50,51}$ The addition of immune checkpoint inhibitors to blinatumomab therapy may therefore enhance its efficacy, and there are several ongoing trials assessing the efficacy and safety of this approach in both adult patients (NCT02879695, NCT03160079, NCT035 12405) and pediatric patients (NCT03605589).

\section{Blinatumomab in the Real World}

Another question to consider is the outcomes for patients who receive blinatumomab in the "real world" outside of the context of clinical trials. Badar and colleagues conducted a retrospective, multicenter trial analyzing outcomes for patients with $\mathrm{R} / \mathrm{R}$ or MRD+ disease who were treated with blinatumomab between $12 / 2014$ and 5/2019. They found that blinatumomab was well tolerated with similar rates of grade 3-4 CRS and neurotoxicity as seen in clinical trials. They also found encouraging results with respect to efficacy. Rate of $\mathrm{CR} / \mathrm{CRi}$ for patients with $\mathrm{R} / \mathrm{R}$ disease was $61 \%$ with $44 \%$ having CR with MRD negativity. Median OS for patients with $\mathrm{R} / \mathrm{R}$ disease was 12.7 months. For patients in remission but with MRD prior to treatment, 75\% achieved MRD negativity and median OS was 34.7 months for this group of patients. $^{52}$ These results support the safety and utility of blinatumomab administered outside of clinical trials. It will be important to continue to monitor patient outcomes over time as more patients are treated with blinatumomab in routine clinical practice. 


\section{Conclusion}

This is an exciting time for research in ALL with several targeted and immune therapies recently approved and currently under investigation. Blinatumomab is one such therapy that has led to improved outcomes for patients with $\mathrm{R} / \mathrm{R}$ and MRD + B-ALL. There are several ongoing areas of study in relation to blinatumomab that will help to further refine our understanding of blinatumomab and its place in therapy. This will continue to enhance our ability to use blinatumomab as effectively as possible and maximize its therapeutic potential.

\section{Disclosure}

Bhavana Bhatnagar reports advisory board honorarium from Novartis, Astellas, Cell Therapeutics, Pfizer, Kite, and research support from Karyopharm Therapeutics and Cell Therapeutics, outside the submitted work.

The authors report no other potential conflicts of interest in this work.

These authors contributed equally to the preparation of the manuscript: Audrey M Sigmund, Kieran D Sahasrabudhe.

\section{References}

1. Hoelzer D, Bassan R, Dombret H, et al. Acute lymphoblastic leukaemia in adult patients: ESMO clinical practice guidelines for diagnosis, treatment and follow-up. Ann Oncol. 2016;27(suppl 5):v69-v82. doi:10.1093/annonc/mdw025

2. Gokbuget N, Dombret H, Ribera JM, et al. International reference analysis of outcomes in adults with B-precursor Ph-negative relapsed/refractory acute lymphoblastic leukemia. Haematologica. 2016;101(12):1524-1533.

3. Gokbuget N, Stanze D, Beck J, et al. Outcome of relapsed adult lymphoblastic leukemia depends on response to salvage chemotherapy, prognostic factors, and performance of stem cell transplantation. Blood. 2012;120(10):2032-2041. doi:10.1182/blood-2011-12-399287

4. Rowe JM. Prognostic factors in adult acute lymphoblastic leukaemia. Br J Haematol. 2010;150(4):389-405.

5. Topp MS, Gökbuget N, Stein AS, et al. Safety and activity of blinatumomab for adult patients with relapsed or refractory B-precursor acute lymphoblastic leukaemia: a multicentre, single-arm, phase 2 study. Lancet Oncol. 2015;16(1):57-66. doi:10.1016/S1470-2045(14)71170-2

6. Gokbuget N, Zugmaier G, Klinger M, et al. Long-term relapse-free survival in a phase 2 study of blinatumomab for the treatment of patients with minimal residual disease in B-lineage acute lymphoblastic leukemia. Haematologica. 2017;102(4):e132-e135. doi:10.33 24/haematol.2016.153957

7. Uckun FM, Jaszcz W, Ambrus JL, et al. Detailed studies on expression and function of CD19 surface determinant by using B43 monoclonal antibody and the clinical potential of anti-CD19 immunotoxins. Blood. 1988;71(1):13-29. doi:10.1182/blood.V71.1.13.13

8. Scheuermann RH, Racila E. CD19 antigen in leukemia and lymphoma diagnosis and immunotherapy. Leuk Lymphoma. 1995;18(5-6):385-397. doi:10.3109/10428199509059636

9. Huehls AM, Coupet TA, Sentman CL. Bispecific T-cell engagers for cancer immunotherapy. Immunol Cell Biol. 2015;93(3):290-296. doi:10.1038/icb.2014.93
10. Bargou R, Leo E, Zugmaier G, et al. Tumor regression in cancer patients by very low doses of a T cell-engaging antibody. Science. 2008;321(5891):974-977. doi:10.1126/science.1158545

11. Kontermann RE. Dual targeting strategies with bispecific antibodies. MAbs. 2012;4(2):182-197. doi:10.4161/mabs.4.2.19000

12. Dreier T, Baeuerle PA, Fichtner I, et al. T cell costimulus-independent and very efficacious inhibition of tumor growth in mice bearing subcutaneous or leukemic human B cell lymphoma xenografts by a CD19-/CD3- bispecific single-chain antibody construct. J Immunol. 2003;170(8):4397-4402. doi:10.40 49/jimmunol.170.8.4397

13. Schlereth B, Quadt C, Dreier T, et al. T-cell activation and B-cell depletion in chimpanzees treated with a bispecific anti-CD19/antiCD3 single-chain antibody construct. Cancer Immunol Immunother. 2006;55(5):503-514. doi:10.1007/s00262-005-0001-1

14. Nagorsen D, Kufer P, Baeuerle PA, et al. Blinatumomab: a historical perspective. Pharmacol Ther. 2012;136(3):334-342. doi:10.1016/j. pharmthera.2012.07.013

15. Goebeler M-E, Knop S, Viardot A, et al. Bispecific T-cell engager (BiTE) antibody construct blinatumomab for the treatment of patients with relapsed/refractory non-hodgkin lymphoma: final results from a phase i study. J Clin Oncol. 2016;34(10):1104-1111. doi:10.1200/ JCO.2014.59.1586

16. Zhu M, Wu B, Brandl C, et al. Blinatumomab, a bispecific T-cell engager $(\operatorname{BiTE}((\mathrm{R})))$ for $\mathrm{CD}-19$ targeted cancer immunotherapy: clinical pharmacology and its implications. Clin Pharmacokinet. 2016;55(10):1271-1288. doi:10.1007/s40262-016-0405-4

17. Dreier T, Lorenczewski G, Brandl C, et al. Extremely potent, rapid and costimulation-independent cytotoxic T-cell response against lymphoma cells catalyzed by a single-chain bispecific antibody. Int J Cancer. 2002;100(6):690-697. doi:10.1002/ijc.10557

18. Kantarjian H, Stein A, Gökbuget N, et al. Blinatumomab versus chemotherapy for advanced acute lymphoblastic leukemia. $N$ Engl $J$ Med. 2017;376(9):836-847. doi:10.1056/NEJMoa160 9783

19. Blincyto ${ }^{\circledR}$ [package insert]. Thousand Oaks, CA: Amgen Inc; 2014.

20. Klinger M, Brandl C, Zugmaier G, et al. Immunopharmacologic response of patients with B-lineage acute lymphoblastic leukemia to continuous infusion of T cell-engaging CD19/CD3-bispecific BiTE antibody blinatumomab. Blood. 2012;119(26):6226-6233. doi:10.11 82/blood-2012-01-400515

21. Choudhry J, Parson M, Wright J. A retrospective review of tocilizumab for management of blinatumomab (a bispecific $\mathrm{T}$ cell engager)-induced cytokine release syndrome (CRS). Blood. 2018;132:5211. doi:10.1182/blood-2018-99-117353

22. Martinelli G, Boissel N, Chevallier P, et al. Complete hematologic and molecular response in adult patients with relapsed/refractory philadelphia chromosome-positive B-precursor acute lymphoblastic leukemia following treatment with blinatumomab: results from a phase ii, single-arm, multicenter study. J Clin Oncol. 2017;35 (16):1795-1802. doi:10.1200/JCO.2016.69.3531

23. King AC, Pappacena JJ, Tallman MS, et al. Blinatumomab administered concurrently with oral tyrosine kinase inhibitor therapy is a well-tolerated consolidation strategy and eradicates measurable residual disease in adults with Philadelphia chromosome positive acute lymphoblastic leukemia. Leuk Res. 2019;79:27-33. doi:10.1016/j. leukres.2019.02.009

24. Assi R, Kantarjian H, Short NJ, et al. Safety and efficacy of blinatumomab in combination with a tyrosine kinase inhibitor for the treatment of relapsed philadelphia chromosome-positive leukemia. Clin Lymphoma Myeloma Leuk. 2017;17(12):897-901. doi:10.1016/j. clm1.2017.08.101

25. Beldjord K, Chevret S, Asnafi V, et al. Oncogenetics and minimal residual disease are independent outcome predictors in adult patients with acute lymphoblastic leukemia. Blood. 2014;123(24):3739-3749. doi:10.1182/blood-2014-01-547695 
26. Berry DA, Zhou S, Higley H, et al. Association of minimal residual disease with clinical outcome in pediatric and adult acute lymphoblastic leukemia: a meta-analysis. JAMA Oncol. 2017;3(7):e170580. doi:10.1001/jamaoncol.2017.0580

27. Brüggemann M, Raff $T$, Flohr $T$, et al. Clinical significance of minimal residual disease quantification in adult patients with standard-risk acute lymphoblastic leukemia. Blood. 2006;107 (3):1116-1123. doi:10.1182/blood-2005-07-2708

28. Topp MS, Kufer P, Gökbuget N, et al. Targeted therapy with the T-cellengaging antibody blinatumomab of chemotherapy-refractory minimal residual disease in B-lineage acute lymphoblastic leukemia patients results in high response rate and prolonged leukemia-free survival. J Clin Oncol. 2011;29(18):2493-2498. doi:10.1200/JCO.2010.32.7270

29. Topp MS, Gökbuget N, Zugmaier G, et al. Long-term follow-up of hematologic relapse-free survival in a phase 2 study of blinatumomab in patients with MRD in B-lineage ALL. Blood. 2012;120 (26):5185-5187. doi:10.1182/blood-2012-07-441030

30. Gokbuget N, Dombret $H$, Bonifacio $M$, et al. Blinatumomab for minimal residual disease in adults with B-cell precursor acute lymphoblastic leukemia. Blood. 2018;131(14):1522-1531.

31. Richard-Carpentier G, Kantarjian HM, Jorgensen JL, et al. Phase II study of blinatumomab in patients with B-cell acute lymphoblastic leukemia (B-ALL) with positive measurable residual disease (MRD). Blood. 2019;134(Supplement 1):1299. doi:10.1182/blood-2019-130283

32. ClonoSEQ cleared for residual cancer testing. Cancer Discov. 2018;8 (12):OF6. doi:10.1158/2159-8290.CD-NB2018-136

33. Dhedin N, Huynh A, Maury S, et al. Role of allogeneic stem cell transplantation in adult patients with $\mathrm{Ph}$-negative acute lymphoblastic leukemia. Blood. 2015;125(16):2486-96; quiz 2586.

34. Gokbuget N, Kneba M, Raff T, et al. Adult patients with acute lymphoblastic leukemia and molecular failure display a poor prognosis and are candidates for stem cell transplantation and targeted therapies. Blood. 2012;120(9):1868-1876. doi:10.1182/blood-2011-09-377713

35. Kebriaei P, Banerjee PP, Ganesh C, et al. Blinatumomab is well tolerated maintenance therapy following allogeneic hematopoietic cell transplantation for acute lymphoblastic leukemia. Blood. 2019;134(Supplement_1):1298. doi:10.1182/blood-2019-125931

36. Kantarjian H, Thomas D, Jorgensen J, et al. Inotuzumab ozogamicin, an anti-CD22-calecheamicin conjugate, for refractory and relapsed acute lymphocytic leukaemia: a phase 2 study. Lancet Oncol. 2012;13(4):403-411. doi:10.1016/S1470-2045(11)70386-2

37. DeAngelo DJ, Stock W, Stein AS, et al. Inotuzumab ozogamicin in adults with relapsed or refractory CD22-positive acute lymphoblastic leukemia: a Phase 1/2 study. Blood Adv. 2017;1(15):1167-1180. doi:10.1182/bloodadvances.2016001925

38. Kantarjian HM, DeAngelo DJ, Stelljes M, et al. Inotuzumab ozogamicin versus standard of care in relapsed or refractory acute lymphoblastic leukemia: final report and long-term survival follow-up from the randomized, Phase 3 INO-VATE study. Cancer. 2019;125(14):2474-2487. doi:10.1002/cncr.32116

39. Maude SL, Laetsch TW, Buechner J, et al. Tisagenlecleucel in children and young adults with B-cell lymphoblastic leukemia. $N$ Engl J Med. 2018;378(5):439-448.

40. Advani AS, Moseley A, O’Dwyer KM, et al. Results of SWOG 1318: a phase 2 trial of blinatumomab followed by pomp (prednisone, vincristine, methotrexate, 6-mercaptopurine) maintenance in elderly patients with newly diagnosed philadelphia chromosome negative B-cell acute lymphoblastic leukemia. Blood. 2018;132(Supplement 1):33. doi:10.1182/blood-2018-99-111992

41. Chiaretti S, Bassan R, Vitale A, et al. Dasatinib-blinatumomab combination for the front-line treatment of adult $\mathrm{Ph}+\mathrm{ALL}$ patients. Updated results of the gimema LAL2116 D-alba trial. Blood. 2019;134(Supplement_1):740. doi:10.1182/blood-2019-128759

42. Richard-Carpentier G, Kantarjian HM, Short NJ, et al. Updated results from the phase ii study of hyper-CVAD in sequential combination with blinatumomab in newly diagnosed adults with B-cell acute lymphoblastic leukemia (B-ALL). Blood. 2019;134 (Supplement_1):3807. doi:10.1182/blood-2019-129657

43. Fleming S, Venn N, Reynolds J, et al. Preliminary minimal residual disease analysis of the australasian leukaemia \& lymphoma group (ALLG) ALL8 study of front-line blinatumomab with chemotherapy in adults with $\mathrm{Ph}$ negative B-cell acute lymphoblastic leukaemia. Blood. 2019;134(Supplement_1):1300. doi:10.1182/blood-2019-132048

44. Ruella M, Maus MV. Catch me if you can: leukemia escape after CD19-directed T cell immunotherapies. Comput Struct Biotechnol J. 2016;14:357-362. doi:10.1016/j.csbj.2016.09.003

45. Jabbour E, Dull J, Yilmaz M. Outcome of patients with relapsed/ refractory acute lymphoblastic leukemia after blinatumomab failure: no change in the level of CD19 expression. Am J Hematol. 2018;93 (3):371-374. doi:10.1002/ajh.24987

46. Haddox CL, Mangaonkar AA, Chen D, et al. Blinatumomab-induced lineage switch of B-ALL with $\mathrm{t}(4: 11)(\mathrm{q} 21 ; \mathrm{q} 23) \mathrm{KMT} 2 \mathrm{~A} / \mathrm{AFF} 1$ into an aggressive AML: pre- and post-switch phenotypic, cytogenetic and molecular analysis. Blood Cancer J. 2017;7(9):e607. doi:10.1038/bcj.2017.89

47. He RR, Nayer Z, Hogan M, et al. Immunotherapy- (blinatumomab-) related lineage switch of KMT2A/AFF1 rearranged B-lymphoblastic leukemia into acute myeloid leukemia/myeloid sarcoma and subsequently into B/myeloid mixed phenotype acute leukemia. Case Rep Hematol. 2019;2019:7394619. doi:10.1155/2019/7394619

48. Wolfl M, Rasche M, Eyrich M, et al. Spontaneous reversion of a lineage switch following an initial blinatumomab-induced ALL-toAML switch in MLL-rearranged infant ALL. Blood Adv. 2018;2 (12):1382-1385. doi:10.1182/bloodadvances.2018018093

49. Zoghbi A, Zur Stadt U, Winkler B, et al. Lineage switch under blinatumomab treatment of relapsed common acute lymphoblastic leukemia without MLL rearrangement. Pediatr Blood Cancer. 2017;64(11):e26594. doi:10.1002/pbc.26594

50. Feucht J, Kayser S, Gorodezki D, et al. T-cell responses against CD19+ pediatric acute lymphoblastic leukemia mediated by bispecific T-cell engager (BiTE) are regulated contrarily by PD-L1 and CD80/CD86 on leukemic blasts. Oncotarget. 2016;7(47):76 902-76919. doi:10.18632/oncotarget.12357

51. Kohnke T, Krupka C, Tischer J, et al. Increase of PD-L1 expressing B-precursor ALL cells in a patient resistant to the CD19/ CD3-bispecific $\mathrm{T}$ cell engager antibody blinatumomab. J Hematol Oncol. 2015;8(1):111. doi:10.1186/s13045-015-0213-6

52. Badar T, Szabo A, Advani AS, et al. Real world outcomes of adult B-cell acute lymphocytic leukemia patients treated with blinatumomab. Blood. 2019;134(Supplement_1):3809. doi:10.1182/ blood-2019-125466 


\section{Publish your work in this journal}

Blood and Lymphatic Cancer: Targets and Therapy is an international, peer-reviewed, open access journal focusing on blood and lymphatic cancer research, identification of therapeutic targets and the optimal use of preventative and integrated treatment interventions to achieve improved outcomes, enhanced survival and quality

Submit your manuscript here: http://www.dovepress.com/blood-and-lymphatic-cancer-targets-and-therapy-journal of life for the cancer patient. The manuscript management system is completely online and includes a very quick and fair peer-review system. Visit http://www.dovepress.com/testimonials.php to read real quotes from published authors. 